\title{
Volatile Compounds from the Bark Bugs Phloea subquadrata and Phloeophana longirostris (Heteroptera: Phloeidae)
}

\author{
Francine S. A. da Fonseca, ${ }^{a, b}$ Adriana T. Salomão, ${ }^{c}$ João Vasconcellos-Neto, ${ }^{c}$ \\ Thiago I. B. Lopes ${ }^{a, d}$ and Anita J. Marsaioli ${ }^{*}, a$
}

${ }^{a}$ Departamento de Química Orgânica, Instituto de Química, Universidade Estadual de Campinas (IQ-Unicamp), CP 6154, 13083-970 Campinas-SP, Brazil

${ }^{b}$ Laboratório de Plantas Medicinais, Instituto de Ciências Agrárias, Universidade Federal de Minas Gerais (ICA-UFMG), 39404-547 Montes Claros-MG, Brazil

'Programa de Pós-graduação em Ecologia, Instituto de Biologia, Universidade Estadual de Campinas (IB-Unicamp), CP 6109, 13083-970 Campinas-SP, Brazil

${ }^{d}$ Instituto Federal de Educação, Ciência e Tecnologia de Mato Grosso do Sul (IFMS), Campus Três Lagoas, 79641-162 Três Lagoas-MS, Brazil

\begin{abstract}
Phloea subquadrata and Phloeophana longirostris are subsocial species that differ from each other in their host plants and degrees of aggregation. Until recently, only ten low-molecular weight compounds, a sesquiterpene, and dimers of (E)-4-oxo-2-hexenal had been reported from the contents of $P$. subquadrata glands. Here, the main goal was to distinguish the volatile compounds released by adult males, adult females and nymphs of the two species. The analyses revealed 103 compounds, of which 44 were exclusive to Phloeophana longirostris and 15 were exclusive to Phloea subquadrata. The data were analyzed by chemometric methods, which discriminated the phloeid species by developmental stage and sex. (E)-2-Hexenal, (E)-4-oxo-2-hexenal and $(E)$-2-octenal were found in both species. Adult individuals were characterized by the presence of methyl 2-methylbutanoate, $(E)$-2-hexenyl acetate and 2-hexenyl butanoate, and nymphs were characterized by 5 -ethyl-2(3H)-furanone and $(E)$-2-octenal. There was chemical distinction between volatiles of adults and nymphs of the two species studied.
\end{abstract}

Keywords: SPME, semiochemicals, glands, Hemiptera

\section{Introduction}

Insects belonging to the suborder Heteroptera (Hemiptera) are characterized by scent glands that produce and store compounds commonly used in intra- and interspecific chemical communication. ${ }^{1}$ In some families, such compounds have been elucidated and well-studied; however, in others, little is known.,3

Phloeidae (Pentatomoidea) is a small family of bugs with only three genera and four species. ${ }^{4}$ Three of these (Phloeophana longirostris, Phloea corticata and Phloea subquadrata) occur exclusively in South America, mainly in Brazil. ${ }^{5}$ They live on tree trunks and feed on the sap of their host plants. Phloeid bark bugs are considered subsocial insects because the females take care of the eggs ${ }^{6}$

*e-mail: anita@iqm.unicamp.br

This article is part of the Special Issue BIOprospecTA-BIOTA. and carry nymphs attached under their abdomen until the beginning of the second instar. ${ }^{7}$ Nymphal development is prolonged and may take almost one year. ${ }^{7,8}$

Phloea subquadrata is associated with trees of the families Myrtaceae, ${ }^{5,8,9}$ Phyllantaceae ${ }^{5}$ and Combretaceae. ${ }^{6}$ Both nymphs and adults may form aggregations on tree trunks. ${ }^{7}$ Phloeophana longirostris has been recorded on plants of several families (Mimosaceae, Combretaceae, Moraceae, Urticaceae, ${ }^{5}$ Euphorbiaceae and Fabaceae). ${ }^{7}$ After leaving the mother, individuals do not show gregarious behavior. $^{7}$

The two species possess highly modified bodies, which are indistinguishable from the tree trunks where they live. They also release an odoriferous secretion when disturbed. ${ }^{7}$ Recently, a study has revealed ten low-molecular weight compounds in the scent glands of Phloea subquadrata, including aldehydes, esters, alkanes and a monocyclic sesquiterpene. Moreover, dimers of (E)-4-oxo-2-hexenal 
were reported for the first time as constituents of the gland secretion in heteropterans. ${ }^{10}$

The objective of this work was to identify the volatile compounds released by adult males, adult females and nymphs of Phloea subquadrata and Phloeophana longirostris to distinguish the chemical patterns between species, developmental stages and sexes.

\section{Experimental}

Insects

The specimens of Phloea subquadrata were collected in the Biological Reserve of Serra do Japi

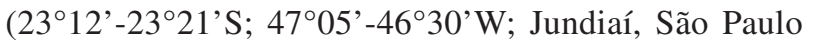
State), and specimens of Phloeophana longirostris were collected from the campus of the University of São Paulo (233' S, 46²43'W; São Paulo, São Paulo State, Brazil). The sampling was made on different dates in 2010, 2011 and 2012. Phloeidae species were identified by the second author (A. T. S.) according to Lent and Jurberg. ${ }^{5}$

A total of 12 adults (6 males and 6 females) and 23 nymphs ( 3 of $1^{\text {st }}$ instar, 7 of $2^{\text {nd }}$ instar, 6 of $3^{\text {rd }}$ instar, 5 of $4^{\text {th }}$ instar and 2 of $5^{\text {th }}$ instar) of Phloea subquadrata were collected. Phloeophana longirostris volatiles were collected from 10 adults ( 6 males and 4 females) and 10 nymphs ( 2 of $2^{\text {nd }}$ instar, 4 of $3^{\text {rd }}$ instar and 4 of $4^{\text {th }}$ instar). The insects were analyzed within $48 \mathrm{~h}$ of being captured. They were kept separately in vials $(20 \mathrm{~mL})$ at $20^{\circ} \mathrm{C}$ until needed.

\section{Sample preparation}

The insects were analyzed under two conditions, undisturbed and disturbed. The specimen under analysis was inserted into a vial $(20 \mathrm{~mL})$ appropriately adapted for the insertion of a solid-phase microextraction (SPME) fiber. The volatile compounds were sampled from the vial headspace (HS) using SPME technique. The specimen was disturbed by rubbing its dorsal region with a glass rod for $5 \mathrm{~s}$. Then, it was left for $60 \mathrm{~s}$ at $20^{\circ} \mathrm{C}$, and the volatiles were trapped for 20 min with a $75 \mu \mathrm{m}$ carboxenpolydimethylsiloxane (PDMS) fiber (Supelco, Inc., Bellefonte, PA, USA) on the SPME sampler. Thermal desorption of the compounds from the fiber to the gas chromatography mass spectrometry (GC-MS) equipment was followed by the analyses of the volatiles. ${ }^{11}$

\section{GC-MS analysis}

The volatiles were analyzed with an Agilent 6890 chromatograph (Palo Alto, CA, USA) equipped with a selective mass detector HP 5973A, electron ionization of $70 \mathrm{eV}$, and a capillary column DB-5 $(30 \mathrm{~m} \times 0.25 \mathrm{~mm} \times 0.25 \mu \mathrm{m})$ of $5 \%$ phenyl-methylsiloxane. Helium was applied as the carrier gas at a flow of $1 \mathrm{~mL} \mathrm{~min}{ }^{-1}$, an injector temperature of $250{ }^{\circ} \mathrm{C}$, and an interface temperature of $280{ }^{\circ} \mathrm{C}$. The initial column temperature was $40{ }^{\circ} \mathrm{C}$ for $3 \mathrm{~min}$, increasing to $290{ }^{\circ} \mathrm{C}$ at a rate of $10{ }^{\circ} \mathrm{C} \mathrm{min}^{-1}$. The $\mathrm{GC}$ liner was appropriate for the SPME analyses, and the mass spectrum analyses screened $\mathrm{m} / \mathrm{z}$ 40-400 in full scan mode. The structures of the chemical constituents were obtained by comparing their retention indices and mass fragmentation patterns with those in the Wiley 275 library and by co-injecting standards.

\section{Partial least squares discriminant analysis (PLS-DA)}

The GC-MS data were evaluated individually by searching for contaminants, signal broadening, small abundances, and other deviations. Peak integration was automatic, and peaks below $0.01 \%$ were not considered in the chemometric analyses. The list of the compounds, their retention times and their relative abundances (Table S1, Supplementary Information section) were used in the chemometric analyses. Partial least squares discriminant analysis (PLS-DA) was applied to 104 samples (52 insects analyzed in duplicate) and 103 compounds (variables) to mean-centered data using Pirouette (v 3.11, Infometrix Inc., PA, USA) software. Leave-one-out cross-validation was performed to select the appropriate factor number. The graphical representations were constructed with Origin 6.0 (OriginLab Corporation, Northampton, MA, USA).

\section{Results and Discussion}

HS-SPME was appropriate for the volatile analysis, avoiding the use of solvents. ${ }^{12,13}$ Undisturbed Phloea subquadrata or Phloeophana longirostris did not emit any detectable compounds. However, after mechanical disturbance, the analyses revealed a total of 103 compounds. Fifty-six compounds were detected in Phloea subquadrata ( $\mathrm{n}=32$ individuals), and 88 compounds were detected in Phloeophana longirostris ( $\mathrm{n}=20$ individuals). Only seven compounds were found in all life stages in both species: (Z)-2-hexenal (9), (E)-2-hexenal (10), decane (24), (E)-2-octenal (32), 1-undecene (36), undecane (37) and dodecane (42). The only exception was the first instar of Phloea subquadrata, in which no compounds were detected. It has been previously demonstrated ${ }^{14,15}$ for the stink bug Nezara viridula (Pentatomidae) that the secretion of the dorsal abdominal glands (DAGs) is virtually absent in newly hatched nymphs. Thus, it is possible that the absence 
of volatiles in first instar nymphs of $P$. subquadrata may be explained by the incipient development of their DAGs.

Phloea subquadrata adults were characterized by the presence of methyl 2-methylbutanoate (6), (E)-2-hexen-1-ol (12), 2,4-hexadienal (15), (E)-2hexenyl acetate (28) and $\alpha$-caryophyllene (54). The compounds 1-penten-3-one (1), 2-ethyl-furan (2), 2-methyl-2-butenal (4), methylhexanoate (17), (Z)-3-hexenyl acetate (25) and $\beta$-humulene (53) were detected only in males, while $(E)$-3-hexenal (8) was detected only in females. 2-Vinylfuran (3), 5-methyl2(3H)-furanone (11), 5-ethyl-2(3H)-furanone (22), (Z)-2-octenal (31), 2-isopropylcyclohexanone (38), 2-propyl cyclohexanone (40), and (E)-2-decenal (46) were detected only in nymphal volatile blends. Second instar nymphs were characterized by the presence of an unknown compound (13), and $3^{\text {rd }}$ instar nymphs showed high abundances of $(E)$-4-oxo-2-hexenal (19). The compounds 2-cyclohexen-1,4-dione (35), (Z)-2-decenal (44), 2,4-decadienal (45) and undecanol (52) were detected only in $4^{\text {th }}$ instar individuals.

The compound (E)-4-oxo-2-hexenal (19) was present in all life stages of Phloea subquadrata; however, (E)-4-oxo2-hexenal dimers were not detected. Interestingly, such dimers had been reported in the gland contents of P. subquadrata. ${ }^{10}$ In that study, it was suggested that these dimers may have a storage function within the scent glands. ${ }^{10}$ Their absence in the secretions of disturbed bugs reinforces this hypothesis. Alternatively, the sampling of dimers may have been limited by the applied technique (SPME).

In Phloeophana longirostris, (E)-2-hexen-1-ol (12), (E)-2-hexenyl acetate (28), 2-octenyl acetate (43), $\beta$-humulene (53), $\beta$-pinene (71), limonene (76), "lilalic" aldehyde (81), $\beta$-elemene (86), d-selinene (93) and $\alpha$-selinene (95) were exclusively detected in adults. Male blends were characterized by the presence of 5-methyl-2(3H)-furanone (11), 3-methyl-2-butenyl acetate (16), tetradecane (51), acetic acid, 2-methylpropyl ester (57), 3-methyl-2-butenal (58), 2-methylbutenyl acetate (61), 2-methylpropyl butanoate (66), decane isomer (74), 2-methyl-5-(2-methyl-2-propenyl)cyclohexanol (75) and epi-bicyclo sesquiphellandrene (88). Twenty-seven compounds were detected exclusively in Phloeophana females: hexenol isomer (60), 3-ethyl2,4-pentadien-1-ol (63), 2-ethyl-2-pentenal (64), pentyl 2-pentenoate (65), (E)-2-heptenal (67), benzaldehyde (68), butyl butanoate (72), 3-oxiranyl-7-oxabicyclo[4.1.0] heptane (78), unknown 6 (79), benzoic acid methyl ester (80), methyl 2-phenylacetate (82), unknown 7 (83) and the terpenes $\alpha$-caryophyllene (54), $\alpha$-copaene (84), $\alpha$-gurjunene (87), $\beta$-gurjunene (89), $\beta$-aromadendrene (90), $\alpha$-aromadendrene (91), $\beta$-selinene (94), $\beta$-cadinene (96), $\beta$-germacrene (97), isoaromadendrene epoxide (98), cedrene oxide (99), humulene epoxide II (100), bisabolene oxide (101), humulene epoxide III (102), and allo-aromadendrene epoxide (103). The compounds vinylfuran (3), (E)-2-pentenal (5), 5-ethyl2(3H)-furanone (22), 2-isopropylcyclohexanone (38), (E)-2-nonenal (39), (E)-2-decenal (46), pentadecane (56), furanone isomer (59), furan isomer (69), 3-methyl1-ethylcyclopentane (70) and 5-methyl-4-hexen-3-one (77) were only detected in nymphs.

Partial least squares discriminant analyses (PLS-DA) ${ }^{16}$ of the volatile compounds were used to provide an overview of the volatile profiles and determine differences between species (Phloea subquadrata and Phloeophana longirostris), life stages (nymph and adult), and sexes (male and female). The results of the models are summarized in Table 1.

The first PLS-DA model for Phloea subquadrata and Phloeophana longirostris was performed with four factors. The model was able to discriminate the species along the first factor (Figure 1). The low variance explained by the first factor revealed the similarity between the two species; only $19.65 \%$ of the variance of the original data was associated with this discrimination. The second factor (13.77\%) could be associated with differences between individuals of the same species. Phloeophana longirostris (88 compounds found) showed a greater diversity of volatile components than Phloea subquadrata (56 compounds), reflecting a larger dispersion along the second factor.

Table 1. Summary of the three PLS-DA models

\begin{tabular}{lccccccccc}
\hline PLS-DA model & Sample & Factor & Variance $/ \%$ & $\mathrm{R}_{\text {val }}$ & $\mathrm{R}_{\text {cal }}$ & $\begin{array}{c}\text { Sample } \\
\text { class 1 }\end{array}$ & $\begin{array}{c}\text { Error } \\
\text { class 1 }\end{array}$ & $\begin{array}{c}\text { Sample } \\
\text { class 2 }\end{array}$ & $\begin{array}{c}\text { Error } \\
\text { class 2 }\end{array}$ \\
\hline 1 & $P S \times P l$ & 4 & 48.04 & 0.8972 & 0.9671 & 20 & 2 & 32 & 1 \\
2 & nymph $\times$ adult & 4 & 47.23 & 0.9501 & 0.9837 & 22 & 0 & 30 & 1 \\
3 & male $\times$ female & 5 & 66.74 & 0.7578 & 0.9902 & 10 & 1 & 12 & 1 \\
\hline
\end{tabular}

Ps: Phloea subquadrata; Pl: Phloeophana longirostris; Variance: variance explained by the PLS-DA model; $\mathrm{R}_{\text {val }}$ correlation coefficient for validation; $\mathrm{R}_{\text {cal }}$ : correlation coefficient for calibration; Samples class: number of samples in the class; Error class: number of errors observed for class in the crossvalidation (leave-one-out). 


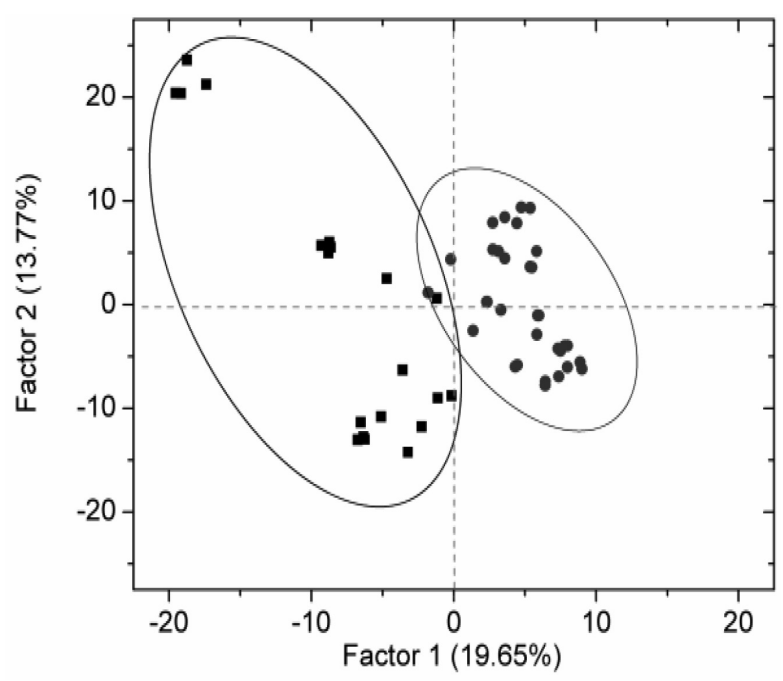

Figure 1. Scores plot for the model (4 factors; $48.04 \%$ of the variance; $\mathrm{R}_{\mathrm{val}}=0.89 ; \mathrm{R}_{\mathrm{cal}}=0.96$ ) based on volatiles from Phloeophana longirostris $(\boldsymbol{\square})$ and Phloea subquadrata $(\mathbf{O})$.

The graphic view of loadings for the first PLS-DA model (Figure 2) revealed the compounds that discriminated the two species. The variables with higher absolute loading values represent a larger contribution to class discrimination. On the one hand, 2-methyl-3-pentenal (7), furane isomer (69), 3-methyl-1-ethylcyclopentane (70), $\beta$-pinene (71) and isoaromadendrene epoxide (98) were associated with Phloeophana longirostris. On the other hand, 5-methyl-2(3H)-furanone (11), $(E)$-4-oxo2-hexenal (19), unknown 2 (23), 5-ethyl-2(5H)-furanone (30), 1-tridecene (47), and tridecane (50) were responsible for the Phloea subquadrata discrimination.

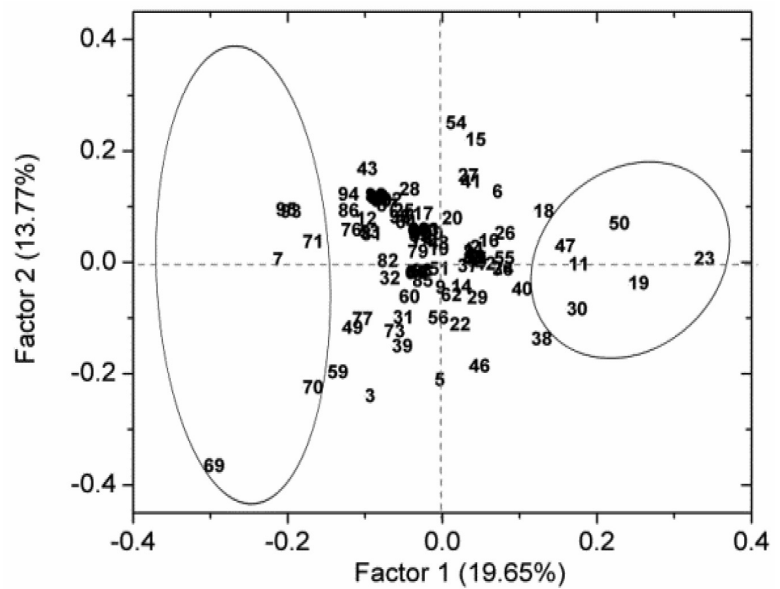

Figure 2. Loadings plot for the first PLS-DA model highlighting the most relevant volatile constituents to discriminate the species Phloeophana longirostris (left) and Phloea subquadrata (right). The compounds are identified in the text.

The second PLS-DA model for nymphs and adults of both species was performed with four factors and discriminated the developmental stage along the first factor
(24.13\% of the variance of the original data), even while analyzing both species together (Figure 3). Additionally, the second factor revealed that it is possible to discriminate adults of both species, as has already been shown by the first PLS-DA model for the species. However, there was only a slight separation between the nymphs of both species.

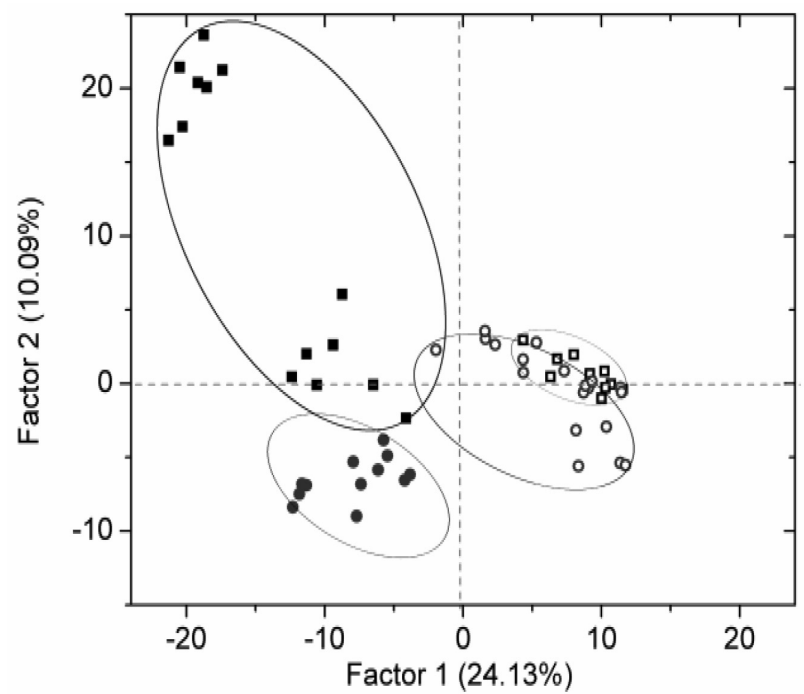

Figure 3. Scores plot for the PLS-DA model based on volatiles from nymphs and adults (4 factors; $47.23 \%$ of the variance; $\mathrm{R}_{\mathrm{val}}=0.95 ; \mathrm{R}_{\mathrm{cal}}=0.98$ ), showing the discrimination between nymphs of Phloea subquadrata $(\bigcirc)$ and Phloeophana longirostris $(\square)$ and adults of Phloea subquadrata $(\bullet$ and Phloeophana longirostris ( $\mathbf{\square})$.

The well-defined separation between nymphs and adults of both species suggest that some of the volatile compounds could be used as developmental stage markers for these bark bugs. The visualization of the loadings for the second PLS-DA model showed a homogeneous distribution of the variables, highlighting the compounds involved in the discrimination of nymphs and adults (Figure 4). (E)-2-Hexen1-ol (12), 2,4-hexadienal (15), 2-octenyl acetate (43), and $\alpha$-caryophyllene (54) were characteristic of adults, while 5-ethyl-2(3H)-furanone (22), (Z)-2-octenal (31), (E)-2-octenal (32), 2-isopropylcyclohexanone (38) and (E)-2-decenal (46) were responsible for the discrimination of nymphs. Differences in the volatiles emitted by adults and nymphs have been reported in different heteropteran families, such as Coreidae ${ }^{17,18}$ and Pentatomidae, ${ }^{19}$ and they might be associated with changes in predator guilds. ${ }^{18}$ However, little is known about natural enemies of Phloeidae. ${ }^{7,9}$

The PLS-DA analysis of adult individuals of both species was performed with five factors, with a variance of $66.74 \%$ explained by the model. The sexes were distributed along the first factor, where females are shown predominantly on the left side of the scores plot in both species and males are shown on the right side (Figure 5). 


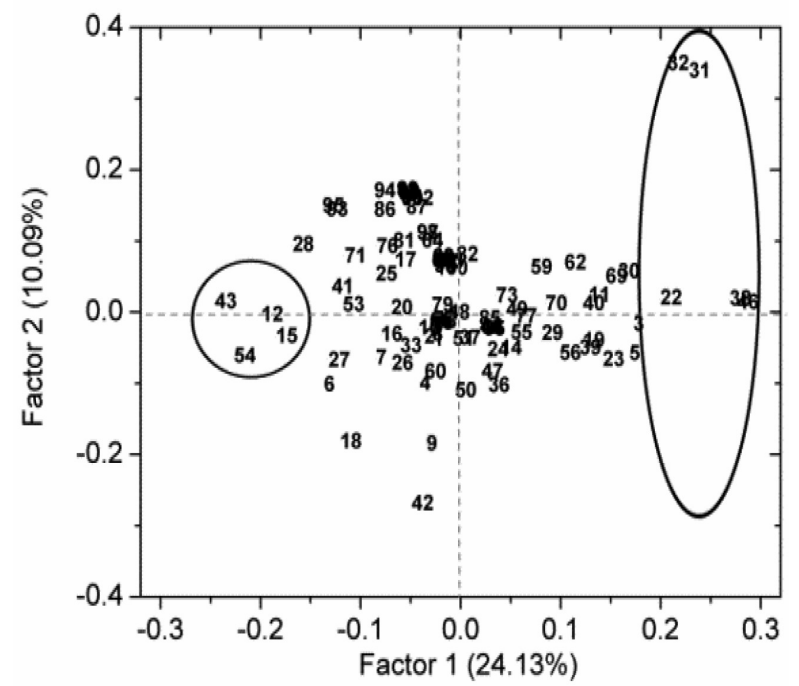

Figure 4. Loadings plot for the second PLS-DA model, highlighting relevant compounds to discriminate nymphal (left) and adult (right) stages in both species. The compounds are identified in the text.

A larger separation between males and females was observed for Phloeophana longirostris in comparison to Phloea subquadrata. In addition, Phloeophana longirostris females had a more disperse pattern, which was attributed to the presence of sesquiterpenes.

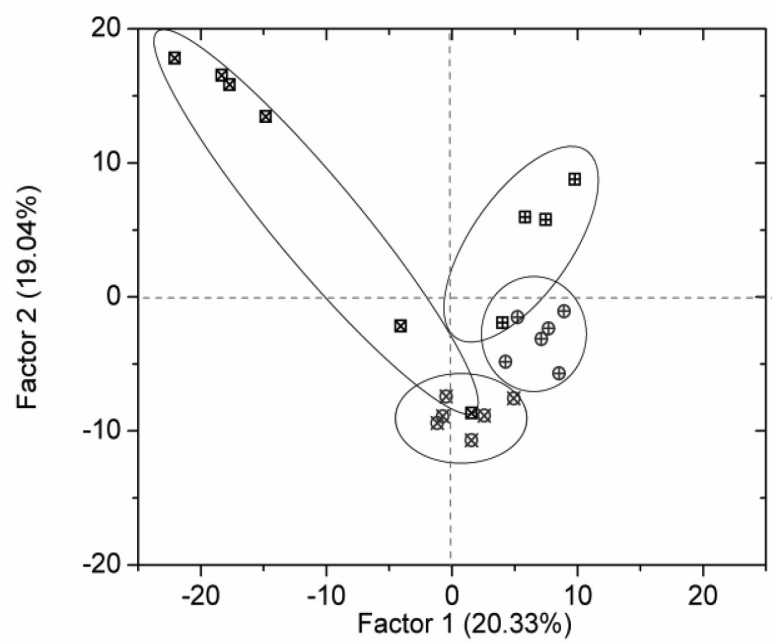

Figure 5. Scores plot for the PLS-DA model built for sex discrimination between phloeid species ( 5 factors; $66.74 \%$ of the variance; $R_{\text {val }}=0.75$; $\left.\mathrm{R}_{\text {cal }}=0.99\right)$, showing female Phloea subquadrata $(\bigotimes)$, female Phloeophana longirostris $(\bigotimes)$, male Phloea subquadrata $(\oplus)$ and male Phloeophana longirostris $(\boxplus)$.

The compounds responsible for grouping females along the first factor were as follows: methyl 3-methylhexanoate (20), hexylacetate (27), $\alpha$-caryophyllene (54) and $\beta$-selinene (94). Among these, only 94 was exclusively detected in Phloeophana longirostris, and the remaining were common to both species. For males, it was possible to note two compounds: 5 -ethyl-2(5H)-furanone $(\mathbf{3 0})$ and $\beta$-humulene (53) (Figure 6), both detected in the two species studied.

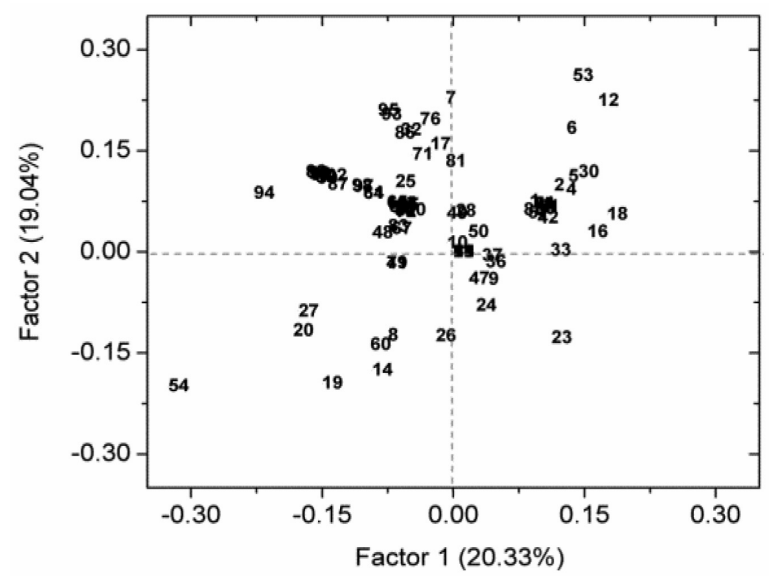

Figure 6. Loadings plot for the third PLS-DA model, highlighting relevant compounds for male and female differentiation in both species. The compounds are identified in the text.

The results of this study strongly suggest a defensive role for the blends emitted by the two species: (i) the chemicals were secreted only in response to disturbance ${ }^{20}$ and (ii) many constituents are found in other heteropteran defensive secretions $s^{2,21,22}$ and are known to have toxic, irritating or deterrent properties. ${ }^{18,23}$ However, these results also suggest that some volatile constituents may have the role of sex pheromones, both because they were absent in nymphs (i.e., sexually immature individuals) and because of the differences detected between male and female adults, mainly in Phloeophana longirostris. It has been demonstrated in some heteropteran families that attractant pheromones derived from the metathoracic glands are stored together with allomones, ${ }^{24,25}$ and may be either produced by males (in some Alydidae ${ }^{26}$ and Lygaeidae) ${ }^{24}$ or females (in some Alydidae ${ }^{25}$ and Miridae). ${ }^{27}$

Differences between male and female Phloeophana were mainly due to the diversity of terpenes in female blends. Since individuals of this species live scattered on the trunks of their host trees, usually at low densities, ${ }^{7}$ sex pheromone blends might have evolved to find mates. Conversely, in Phloea subquadrata, groups formed by nymphs and adults of both sexes can be found on trunks. It was also observed that individuals within groups disperse after being disturbed, ${ }^{7}$ but it is not clear if this behavior is elicited by volatiles from nymphs or adults, or both. Thus, in this species, the compounds could act as both aggregation and alarm pheromones. Multimodal signaling systems are known in other species in Heteroptera, where the function of the compounds changes according to the concentration at which they are emitted. ${ }^{3,14}$ Both electroantennographic analyses and behavioral tests will 
be necessary to verify the biological role of the compounds found in this study.

\section{Conclusions}

The chemical composition of the volatiles emitted by nymphs and adults of Phloea subquadrata and Phloeophana longirostris was explored. PLS-DA was successfully applied to the GC-MS chemical profile from both species and showed the different chemical patterns between species, developmental stages and sexes. The analyses also revealed intra- and interspecific markers, such as unsaturated aldehydes and oxo-aldehydes in nymphs and acetyl derivatives and terpenes in adults. The variety of compounds emitted after stimulation shows the complexity of the chemical communication system in Phloeidae. Here, we propose that chemical differences between the two species may be associated with differences in their natural history. Thus, besides suggesting a defensive role for the volatile blends, we raise the hypothesis that some constituents may also act as a sex pheromone in Phloeophana longirostris and as aggregation and alarm pheromones in Phloea subquadrata. It is hoped that further research will provide additional understanding of the chemical communication in Phloeidae.

\section{Supplementary Information}

Supplementary information containing the relative abundance of the volatiles and the total ion chromatograms (GC-MS/SPME) is available free of charge at http://jbcs.sbq.org.br as a PDF file.

\section{Acknowledgments}

The authors are indebted to CNPq for grants (307885/2013-5), CAPES for the scholarship to A. T. S., and UFMG for the leave of absence of F. S. A. F. Comments by the two anonymous reviewers greatly improved the original manuscript.

\section{References}

1. Schuh, R. T.; Slater, J. A.; True Bugs of the World (Hemiptera: Heteroptera): Classification and Natural History; Cornell University Press: Ithaca, USA, 1995.

2. Aldrich, J. R.; Annu. Rev. Entomol. 1988, 33, 38.

3. Millar, J. G.; Top. Curr. Chem. 2005, 240, 37.

4. Grazia, J.; Schuh, R. T.; Wheeler, W. C. P.; Cladistics 2008, 24, 932.
5. Lent, H.; Jurberg J.; Rev. Bras. Biol. 1965, 25, 123.

6. Guilbert, E.; Eur. J. Entomol. 2003, 100, 61.

7. Salomão, A. T.; Postali, T. C.; Vasconcellos-Neto, J. In Novos Olhares, Novos Saberes sobre a Serra do Japi: Ecos de sua Biodiversidade; Vasconcellos-Neto, J.; Polli, P. R.; PenteadoDias, A. M., eds.; Editora CRV: Curitiba, Brasil, 2012, p. 321.

8. Bernardes, J. L. C.; Grazia, J.; Barcellos, A.; Salomão, A. T.; Iheringia, Sér. Zool. 2005, 95, 415.

9. Salomão, A.; Vasconcellos-Neto, J.; Environ. Entomol. 2010, 39, 1724.

10. da Fonseca, F. S. A.; Medeiros, M.; Salomão, A. T.; Vasconcellos-Neto, J.; Marsaioli, A. J.; J. Braz. Chem. Soc. 2016, 27, 1459.

11. Valente, A. L. P.; Augusto, F.; Quim. Nova 2000, 23, 523.

12. Arthur, C. L.; Pawliszyn, J.; Anal. Chem. 1990, 62, 2145.

13. Pawliszyn, J.; TrAC, Trends Anal. Chem. 1995, 14, 113.

14. Lockwood, J. A.; Story, R. N.; Ann. Entomol. Soc. Am. 1985, $78,474$.

15. Pavis, C.; Malosse, C.; Ducrot, P. H.; Descoins, C.; J. Chem. Ecol. 1994, 20, 2213.

16. Zhang, Z. M.; Wu, W. W.; Li, G. K.; J. Chromatogr. Sci. 2009 , 47, 292.

17. Blatt, S. E.; Borden, J. H.; Pierce Jr., H. D.; Gries, R.; Gries, G.; J. Chem. Ecol. 1998, 24, 1013.

18. Prudic, K. L.; Noge, K.; Becerra, J. X.; J. Chem. Ecol. 2008, $34,734$.

19. Fávaro, C. F.; Rodrigues, M. A. C. M.; Aldrich, J. R.; Zarbin, P. H. G.; J. Braz. Chem. Soc. 2011, 22, 58.

20. Krall, B. S.; Zilkowski, B. W.; Kight, S. L.; Bartelt, R. J.; Whitman, D. W.; J. Chem. Ecol. 1997, 23, 1951.

21. Moraes, M. C. B.; Pareja, M.; Laumann, R. A.; Borges, M.; Neotrop. Entomol. 2008, 37, 489.

22. Farine, J. P.; Everaerts, C.; Brossut, R.; le Quére, J. L.; Biochem. Syst. Ecol. 1993, 21, 363.

23. Gunawardena, N. E.; Bandumathie, M. K.; J. Chem. Ecol. 1993, 19, 851; Noge, K.; Prudic, K. L.; Becerra, J. X.; J. Chem. Ecol. 2012, 38, 1050.

24. Aldrich, J. R.; Oliver, J. E.; Taghizadeh, T.; Ferreira, J. T. B.; Liewehr, D.; Chemoecology 1999, 9, 63.

25. Aldrich, J. R.; Zhang, A.; Oliver, J. E.; Can. Entomol. 2000, 132,915 .

26. Leal, W. S.; Higuchi, H.; Mizutani, N.; Nakamori, H.; Kadosawa, T.; Ono, M.; J. Chem. Ecol. 1995, 21, 973.

27. Smith, R. F.; Pierce Jr., H. D.; Borden, J. H.; J. Chem. Ecol. 1991, 17, 1437.

Submitted: October 10, 2016 Published online: February 14, 2017 